\title{
ANÁLISE DAS DIMENSÕES DOS AMBIENTES DE UM CONJUNTO HABITACIONAL PARA IDOSOS
}

\author{
ANÁLISIS DE LAS DIMENSIONES DE LOS AMBIENTES DE UN COMPLEJO DE VIVIENDAS PARA \\ ADULTOS MAYORES
}

ANALYSIS OF THE ENVIRONMENTAL DIMENSIONS IN A HOUSING COMPLEX FOR THE ELDERLY

KUNST, MARINA DE HOLANDA

Doutoranda em Design, Universidade Federal de Pernambuco. E-mail marinakunst7@hotmail.com

\section{BRANDÃO, JOSÉ (ZECA)}

Pós-doutor, Universidade Federal de Pernambuco. E-mail zecabrandao@hotmail.com

PAIVA, MARIE MONIQUE BRUĖRE

Doutora em Design, Universidade Federal de Pernambuco.E-mail mariem.paiva@gmail.com

\author{
VILLAROUCO, VILMA \\ Doutora em Engenharia, Universidade Federal de Pernambuco.E-mail vilma.villarouco@ufpe.br
}

\begin{abstract}
RESUMO
Três quartos da população brasileira vivem em áreas urbanas, situação que acarreta inúmeros problemas sociais, entre os quais a acentuada urbanização dos idosos em situação de vulnerabilidade. Neste contexto, e visando prover moradia adequada para a população idosa com menor poder aquisitivo, foi desenvolvido o Programa Habitacional Cidade Madura no estado da Paraíba, permitindo a vivência próxima a equipamentos urbanos necessários à vida cotidiana. Atenta à questão da adequação dos ambientes residenciais para esta população que envelhece, a pesquisa apresentada neste artigo tem como objetivo avaliar e discutir aspectos dimensionais das habitações e unidade de saúde de um dos conjuntos habitacionais do programa, pondo o foco nas necessidades mais específicas do sujeito alvo do empreendimento. 0 trabalho apresenta preocupações com a satisfação do idoso residente, adotando uma metodologia que compreendeu a aplicação de questionários aos ocupantes, associada à análise dos espaços segundo as normas municipais e de acessibilidade vigentes, bem como a avaliação dimensional baseada em critérios antropométricos. Dentre os principais resultados encontrados estão inadequações de arranjo do mobiliário, as reduzidas dimensões de alguns ambientes e problemas de acessibilidade.
\end{abstract}

PALAVRAS-CHAVE: habitação; idoso; avaliação dimensional.

\section{RESUMEN}

Tres cuartas partes de la población brasileña viven en zonas urbanas, situación que genera numerosos problemas sociales, entre los que destaca la marcada urbanización de las personas mayores en situación de vulnerabilidad. En este contexto, y con el objetivo de brindar una vivienda adecuada a la población anciana con menor poder adquisitivo, se desarrolló el Programa de Vivienda Ciudad Madura en el estado de Paraíba, que permite vivir cerca de utilitarios urbanos necesario para la vida diaria. Atentos a la cuestión de la adecuación de los espacios residenciales para esta población que envejece, la investigación presentada en este artículo tiene como objetivo evaluar y discutir aspectos dimensionales de la vivienda y la unidad de salud de uno de los conjuntos habitacionales del programa, enfocándose en las necesidades más específicas del sujeto destino de la empresa. El trabajo presenta inquietudes con la satisfacción del anciano residente, adoptando una metodología que incluyó la aplicación de cuestionarios a los ocupantes, asociados al análisis de los espacios según las normas municipales y de accesibilidad vigentes, así como la valoración dimensional en base a criterios antropométricos. Entre los principales resultados se encuentran la inadecuada disposición del mobiliario, las reducidas dimensiones de algunos espacios y los problemas de accesibilidad.

PALABRAS CLAVE: vivienda; anciano; evaluación dimensional.

\section{ABSTRACT}

Three quarters of the Brazilian population live in urban areas, a situation that causes numerous social problems, among which the strong urbanization of the elderly in a situation of vulnerability. In this context, and aiming to provide adequate housing for the elderly population with lower acquisitive power, the Cidade Madura Housing Program was developed in the state of Paraiba, allowing the living close to the urban equipment needed for daily life. Paying attention to the issue of adapting residential environments for this aging population, the research presented in this article aims to evaluate and discuss dimensional aspects of the housing and health unit of one of the program's housing complexes, focusing on the more specific needs of the target subject of the project. The work presents concerns with the satisfaction of the elderly resident, adopting a methodology that included the application of questionnaires to the occupants, associated with the analysis of the spaces according to the current municipal and accessibility regulations, as well as the dimensional evaluation based on anthropometric criteria. Among the main results found are inadequacies of furniture arrangement, small size of some rooms and accessibility problems.

KEYWORDS: housing; elderly; dimensional assessment. 


\section{INTRODUÇÃO}

A população mundial vem envelhecendo e a expectativa de vida registra índices de crescimento não apenas em países desenvolvidos, mas também naqueles em processo de crescimento econômico e social. A literatura especializada, jornais, revistas e sites da internet noticiam com frequência os recordes de longevidade. Até 2025, segundo a Organização Mundial da Saúde, o Brasil será o sexto país do mundo em número de idosos, configurando-se num grande desafio frente às particularidades e dificuldades trazidas pelo envelhecimento populacional, impactando inclusive a saúde pública em seu contexto social. Entre 1980 e 2000 a população com 60 anos ou mais cresceu 7,3 milhões, totalizando mais de 14,5 milhões em 2000. O aumento da expectativa média de vida também aumentou acentuadamente no país. Este aumento do número de anos de vida, no entanto, precisa ser acompanhado de melhoria ou manutenção da saúde e da qualidade de vida (WHO, 2005).

Essa longevidade tem implicações importantes em diversos aspectos da pessoa idosa, trazendo consequências sérias nas diferentes dimensões da vida humana, física, psíquica e social (PASCHOAL, 2006). Dentre as principais alterações corporais enfrentadas encontram-se, com variações de intensidade: fraca (gosto, olfato e cinestesia), forte (tato, conforto térmico e dor), a muito forte (visão, audição e equilíbrio) prejudicando a interação do idoso com o ambiente construído (PAIVA, 2012).

A nova condição do indivíduo que envelhece traz também demandas que emergem quando a idade não vem acompanhada de incapacidades, nem situação de dependência. Pessoas acima dos 60 anos completamente ativas tornam-se consumidores potenciais nos negócios de turismo, lazer, academias, produtos e serviços de estética fazendo despontar inclusive novos nichos de mercado, como se registra no ramo imobiliário. Nessa perspectiva, iniciativas de condomínios ou repúblicas para viver entre amigos (LABORDE, 2016) são adotadas por grupos de idosos, que veem nas novas estratégias de morar, um caminho para prover bem-estar nesta fase da vida.

Em matéria recente, Leite (2019) aborda o conceito de Cohousing, como um modelo de moradia compartilhada para idosos, destacando que há espaços comuns na habitação, mas também ambientes individualizados para manutenção da privacidade desejada. A matéria aponta que "o cohousing é mais do que um residencial convencional porque tem uma proposta pra lá de especial: incentivar os vínculos afetivos, a troca de serviços e especialmente de experiências".

A publicação cita a dissertação de mestrado de Simone Gueiros Leite de 2017, que classifica como novo idoso um indivíduo longevo, independente financeiramente, ativo, que goza de boa saúde e cada vez mais opta por morar sozinho ou com o cônjuge. "Segundo Simone, a condição de idoso significa um recomeço para indivíduos ativos, com a possibilidade de continuar morando em sua própria casa com a vantagem de criar laços afetivos com os vizinhos, por conta da proximidade" (LEITE, 2019). A dissertação de Leite (2017) trata de uma pesquisa com pessoas idosas de classe alta na cidade do Recife, identificando predominância dos domicílios unipessoais na amostra estudada.

A preocupação com a moradia é de grande importância e, neste contexto, destaca-se a adequação dos ambientes aos idosos, notadamente no que se refere ao reforço de seus sentimentos de pertencimento e identidade, possibilitando que se reconheçam e dominem o espaço, principalmente aquele de caráter residencial, no qual a maior parte de suas referências vão se concentrar (HAZIN, 2012; TORRES, 2019). Nesse contexto, é essencial se ter em mente o papel fundamental do ambiente na qualidade de vida e no bem-estar dos seres humanos, podendo ser definido como um conjunto de atributos físicos, sensoriais, cognitivos, afetivos, espirituais, climáticos e funcionais dos quais o usuário faz parte, pois circundam o seu dia a dia.

Inserido nesta temática e entendendo que as características dos espaços em suas diversas vertentes impactam na satisfação dos usuários, este artigo tem como objetivo apresentar e discutir as questões dimensionais de ambientes em um conjunto habitacional para idosos na cidade de João Pessoa, abrangendo os espaços do posto médico e das unidades residenciais, identificando possíveis não conformidades, tanto sob o aspecto da legislação quanto no que se refere ao atendimento de necessidades dos usuários pelos espaços pesquisados.

A definição do empreendimento na pesquisa que origina o presente artigo, deve-se à importância da iniciativa em esfera pública. A experiência pioneira do programa Cidade Madura, idealizado e criado pelo Governo do Estado da Paraíba para atender idosos, serviu de modelo para o estado do Paraná, que criou o 'Programa Viver Mais Paraná'. O projeto social foi lançado pelo governo do estado, em outubro de 2019 na cidade de Ponta Grossa (PARAíBA, 2019). 


\section{HABITAÇÃO PARA O IDOSO - REVISÃO DA LITERATURA}

O marco teórico que ancora este artigo procurou identificar questões que envolvem o usuário da pesquisa (a pessoa idosa) e sua moradia, notadamente sob a perspectiva do morar sozinho (aging in place), sua qualidade de vida, sua segurança, sua satisfação e seu bem-estar. Devido à vasta literatura nesse sentido foram compilados e apostos em quadros as investigações nacionais (Quadro 1) e estrangeiras (Quadro 2) que mais se adequaram ao estudo em questão. Os autores e títulos citados exibem pesquisas que relacionam a pessoa idosa e suas necessidades em relação à habitação, indicam interferências de barreiras arquitetônicas, de dimensionamento das circulações, de orientação espacial e demais aspectos relacionados aos ambientes privativos e espaços de uso comum em conjuntos habitacionais. O recorte temporal adotado para essa revisão correspondeu aos últimos cinco anos para publicações nacionais e três anos para as internacionais.

Quadro 1: Síntese de investigações nacionais em habitações voltadas ao usuário idoso.

\begin{tabular}{|c|c|c|c|c|}
\hline Autor(es) & Ano & Título & $\begin{array}{l}\text { Resumo da pesquisa e } \\
\text { instrumentos usados }\end{array}$ & $\begin{array}{c}\text { Contribuições para a pesquisa } \\
\text { atual }\end{array}$ \\
\hline $\begin{array}{l}\text { COSTA, Francine Melo } \\
\text { da; NAKATA, Priscila } \\
\text { Tadei; MORAIS, Eliane } \\
\text { Pinheiro de }\end{array}$ & 2015 & $\begin{array}{l}\text { Estratégias desenvolvidas } \\
\text { pelos idosos residentes } \\
\text { na comunidade para } \\
\text { morarem sozinhos }\end{array}$ & $\begin{array}{l}\text { - análise das estratégias dos } \\
\text { idosos para morar sozinhos; } \\
\text { - uso de entrevistas e técnica de } \\
\text { análise de conteúdo temática } \\
\text { para coleta dos dados }\end{array}$ & $\begin{array}{l}\text { - importância de coletar informações } \\
\text { quanto às estratégias adotadas pelo } \\
\text { idoso ao escolher morar sozinho } \\
\text { - compreensão do comportamento } \\
\text { frente ao processo de envelhecimento }\end{array}$ \\
\hline $\begin{array}{l}\text { TESTON, Elen Ferraz; } \\
\text { CALDAS, Celia Pereira; } \\
\text { MARCON, Sonia Silva }\end{array}$ & 2015 & $\begin{array}{l}\text { Condomínio para idosos: } \\
\text { condições de vida e } \\
\text { saúde de residentes } \\
\text { nesta nova modalidade } \\
\text { habitacional }\end{array}$ & $\begin{array}{l}\text { - comparação de características } \\
\text { sociodemográficas e de saúde } \\
\text { de idosos residentes em um } \\
\text { Condomínio e do Idoso em uma } \\
\text { comunidade } \\
\text { - satisfação com os serviços } \\
\text { médicos e realização de exames }\end{array}$ & $\begin{array}{l}\text { - existência de lacuna relacionada à } \\
\text { política habitacional ferramenta-chave } \\
\text { para o planejamento do cuidado } \\
\text { integral ao idoso de baixa renda; } \\
\text { - importância da análise das } \\
\text { características sociodemográficas }\end{array}$ \\
\hline $\begin{array}{l}\text { YOSHIDA, Débora } \\
\text { Mituuti; MAGAGNIN, } \\
\text { Renata Cardoso }\end{array}$ & 2016 & $\begin{array}{l}\text { Identificação do grau de } \\
\text { acessibilidade espacial } \\
\text { em apartamentos } \\
\text { destinados a idosos }\end{array}$ & $\begin{array}{l}\text { - avaliação do grau de } \\
\text { acessibilidade espacial do } \\
\text { ambiente residencial habitado } \\
\text { - utilização da análise do } \\
\text { deslocamento linear e utilização } \\
\text { dos ambientes por usuário de } \\
\text { cadeira de roda }\end{array}$ & $\begin{array}{l}\text { - inexistência de aplicação das normas } \\
\text { técnicas vigentes sobre acessibilidade } \\
\text { durante a construção do edifício; } \\
\text { - resultados podem subsidiar políticas } \\
\text { públicas para programas e novos } \\
\text { habitacionais }\end{array}$ \\
\hline $\begin{array}{l}\text { GUEDES, Elaine C. N; } \\
\text { LEMOS, Thayna R } \\
\text { Sousa; CANDEIA, } \\
\text { Normanda N; SILVA, } \\
\text { Haydêe C; NEVES, } \\
\text { Rafaela E Freitas }\end{array}$ & 2017 & $\begin{array}{l}\text { Moradia digna no projeto } \\
\text { habitacional Cidade } \\
\text { Madura: uma questão de } \\
\text { mobilidade e acesso no } \\
\text { envelhecimento ativo }\end{array}$ & $\begin{array}{l}\text { - apresentação da estrutura de } \\
\text { mobilidade e acesso oferecido } \\
\text { ao idoso do projeto habitacional } \\
\text { "Cidade Madura" a partir do } \\
\text { olhar dos moradores }\end{array}$ & $\begin{array}{l}\text { - satisfação dos idosos com a moradia } \\
\text { atual quanto à estrutura de mobilidade } \\
\text { e acesso oferecido; } \\
\text { - espaços oportunizam as relações } \\
\text { pessoais e sociais }\end{array}$ \\
\hline $\begin{array}{l}\text { SILVA, Nayara Mendes; } \\
\text { PORTES, Filipe } \\
\text { Augusto; MONTEIRO; } \\
\text { Luzia Cristina Antoniossi }\end{array}$ & 2018 & $\begin{array}{l}\text { Vila Dignidade de } \\
\text { Araraquara na percepção } \\
\text { de seus moradores: } \\
\text { habitação amiga do } \\
\text { idoso? }\end{array}$ & $\begin{array}{l}\text { - análise da percepção dos } \\
\text { moradores sobre as condições } \\
\text { de moradia do Vila Dignidade; } \\
\text { - aplicação de entrevistadas com } \\
\text { os moradores } \\
\end{array}$ & $\begin{array}{l}\text { - existência de aspectos que } \\
\text { comprometem a segurança e o } \\
\text { conforto dos idosos (contraria } \\
\text { princípios norteadores do próprio } \\
\text { programa); }\end{array}$ \\
\hline $\begin{array}{l}\text { RODRIGUES, Rodrigo; } \\
\text { IMAI, César }\end{array}$ & 2019 & $\begin{array}{l}\text { Identificação de } \\
\text { demandas de projeto em } \\
\text { apartamento para } \\
\text { usuários idosos por meio } \\
\text { de modelos físicos }\end{array}$ & $\begin{array}{l}\text { - foco nas necessidades dos } \\
\text { idosos em ambientes } \\
\text { habitacionais; } \\
\text { - interação do idoso com o } \\
\text { protótipo foi satisfatória; } \\
\text { - entrevistas e questionários } \\
\text { insuficientes para captar a } \\
\text { satisfação dos idosos com o } \\
\text { ambiente habitacional } \\
\end{array}$ & $\begin{array}{l}\text { - evidência da necessidade de aplicar } \\
\text { outras ferramentas para a pesquisa; } \\
\text { - uso de protótipos facilita a } \\
\text { identificação de problemas na } \\
\text { moradia. }\end{array}$ \\
\hline $\begin{array}{l}\text { LUCREDI, Victor } \\
\text { Rüegger }\end{array}$ & 2019 & $\begin{array}{l}\text { Habitação para idosos: } \\
\text { programa de locação } \\
\text { social nos centros } \\
\text { históricos de São Paulo } \\
\text { (Brasil) e Barcelona } \\
\text { (Espanha) }\end{array}$ & $\begin{array}{l}\text { - avaliação da habitação para } \\
\text { idosos dos Programas de } \\
\text { Locação Social em centros } \\
\text { históricos quanto à qualidade da } \\
\text { habitação; } \\
\text { - proposição de diretrizes } \\
\text { projetuais para subsidiar estes } \\
\text { programas }\end{array}$ & $\begin{array}{l}\text { - existência de demanda por habitação } \\
\text { social em centros históricos nas } \\
\text { últimas décadas; } \\
\text { - maioria das unidades de habitação } \\
\text { são satisfatórias e os equipamentos } \\
\text { coletivos estão próximos da habitação. }\end{array}$ \\
\hline $\begin{array}{l}\text { SANTOS, Raquel } \\
\text { Ferreira dos }\end{array}$ & 2019 & $\begin{array}{l}\text { Implantação de } \\
\text { empreendimento } \\
\text { habitacional para idosos } \\
\text { com baixa renda no } \\
\text { município de Marabá/PA }\end{array}$ & $\begin{array}{l}\text { - desenvolvimento de projeto de } \\
\text { intervenção para implantação de } \\
\text { residencial para idosos baixa } \\
\text { renda; } \\
\text { - estudo com idosos saudáveis, } \\
\text { lúcidos e autônomos para } \\
\text { atividades diárias e idosos que } \\
\text { necessitam de cuidados }\end{array}$ & $\begin{array}{l}\text { - avaliação das diretrizes adotadas } \\
\text { para cohousing; } \\
\text { - atenção à qualidade de vida aos } \\
\text { idosos provendo espaços como } \\
\text { redário, jardins, horta comunitária, } \\
\text { sala de jogos e atividades diversas. }\end{array}$ \\
\hline
\end{tabular}


Quadro 2: Síntese de investigações internacionais em habitações voltadas ao usuário idoso.

\begin{tabular}{|c|c|c|c|c|}
\hline Autor(es) & Ano & Título & $\begin{array}{l}\text { Resumo da pesquisa e } \\
\text { instrumentos usados }\end{array}$ & $\begin{array}{l}\text { Contribuições para a pesquisa } \\
\text { atual }\end{array}$ \\
\hline RIEH, Sun-Young & 2018 & $\begin{array}{l}\text { Post-occupancy evaluation } \\
\text { of urban public housing in } \\
\text { Korea: Focus on experience } \\
\text { of elderly females in the } \\
\text { ageing society }\end{array}$ & $\begin{array}{l}\text { - avaliação de habitações } \\
\text { urbanas alugadas por meio da } \\
\text { avaliação pós-ocupação de } \\
\text { seis projetos habitacionais } \\
\text { públicos na Coréia; } \\
\text { - uso questionários e } \\
\text { entrevistas }\end{array}$ & $\begin{array}{l}\text { - alteração da planta (flexibilização } \\
\text { dos ambientes); } \\
\text { - acessibilidade: considerar a } \\
\text { presença de um cuidador e um } \\
\text { aplicativo flexível, dependendo do } \\
\text { ciclo de vida de idosos }\end{array}$ \\
\hline $\begin{array}{l}\text { RONCAGLIOLO } \\
\text { CERUTI, César Virgilio } \\
\text { M; LLONTOP CASSINA, } \\
\text { Romina A; NEGRÓN } \\
\text { RONCAL, Daniel } \\
\end{array}$ & 2018 & $\begin{array}{l}\text { Proyecto residencial para el } \\
\text { adulto mayor "La Villa Alta } \\
\text { Bujama - Residencial } \\
\text { Resort }\end{array}$ & $\begin{array}{l}\text { - desenvolvimento de novo } \\
\text { produto imobiliário voltado } \\
\text { para idosos }\end{array}$ & $\begin{array}{l}\text { - consideração de remoção de } \\
\text { barreiras arquitetônicas, integração na } \\
\text { sociedade, assistência médica e } \\
\text { sustentabilidade; } \\
\text { - projeto baseado em experiências } \\
\text { internacionais }\end{array}$ \\
\hline $\begin{array}{l}\text { LEUNG, Mei-yung; } \\
\text { FAMAKIN, Ibukun } \\
\text { Oluwadara; WANG, } \\
\text { Chendi }\end{array}$ & 2019 & $\begin{array}{l}\text { Developing an integrated } \\
\text { indoor built environment- } \\
\text { quality of life model for the } \\
\text { elderly in public and } \\
\text { subsidized housing }\end{array}$ & $\begin{array}{l}\text { - desenvolvimento de modelo } \\
\text { integrado de qualidade de } \\
\text { vida em ambiente interno } \\
\text { construído para idosos em } \\
\text { conjuntos habitacionais } \\
\text { públicos e subsidiados }\end{array}$ & $\begin{array}{l}\text { - iluminação e cor induzem relações } \\
\text { sociais; preocupação com distância e } \\
\text { corrimãos; } \\
\text { - proposição de curta distância para a } \\
\text { atividade física de idosos (requisitos } \\
\text { mínimos de espaçamento); } \\
\text { - influência do tamanho corporal dos } \\
\text { idosos para fornecimento de móveis }\end{array}$ \\
\hline $\begin{array}{l}\text { RODRIGUES, José } \\
\text { Lucas S; MONTEIRO, } \\
\text { Aline G Sousa; LIMA, } \\
\text { Erson K Araújo; SILVA, } \\
\text { Geymeesson B }\end{array}$ & 2020 & $\begin{array}{l}\text { Analysis of housing in the } \\
\text { axes of accessibility and } \\
\text { functionality of a housing } \\
\text { unit designed for the elderly }\end{array}$ & $\begin{array}{l}\text { - análise da habitabilidade de } \\
\text { uma unidade habitacional em } \\
\text { um condomínio projetado para } \\
\text { idosos }\end{array}$ & $\begin{array}{l}\text { - diretrizes de acessibilidade atende } \\
\text { às necessidades dos idosos, mas não } \\
\text { aquelas de funcionalidade; } \\
\text { - projeto inadequado para os idosos } \\
\text { como forma a estimulá-los a vivenciar } \\
\text { o espaço }\end{array}$ \\
\hline
\end{tabular}

Fonte: Autores, 2020.

As pesquisas compreendidas no recorte temporal proposto para análise das literaturas nacional e estrangeira, indicam preocupação quanto à temática da habitação e do idoso, principalmente no tocante aos aspectos de políticas públicas habitacionais, acessibilidade, segurança e socialização. Ressalta-se também ser fundamental a prática de análise e intervenção espacial nas atuais moradias, por meio de metodologias adequadas para ambientes físicos, bem como de aplicação de ferramentas como questionário e/ou entrevista com os seus moradores idosos.

\section{RESULTADOS E DISCUSSÃO}

Caracterizado como um estudo de caso; aqui entendido como um estudo que pesquisa um fenômeno atual da realidade, envolvendo várias técnicas qualitativas; recorta-se o Conjunto Habitacional Cidade Madura, na cidade de João Pessoa, para o presente artigo. A edificação abriga o posto médico e a habitação-padrão, que agrega duas unidades conjugadas (Figura 1).

Figura 1: Planta de Locação do Conjunto habitacional Cidade Madura.

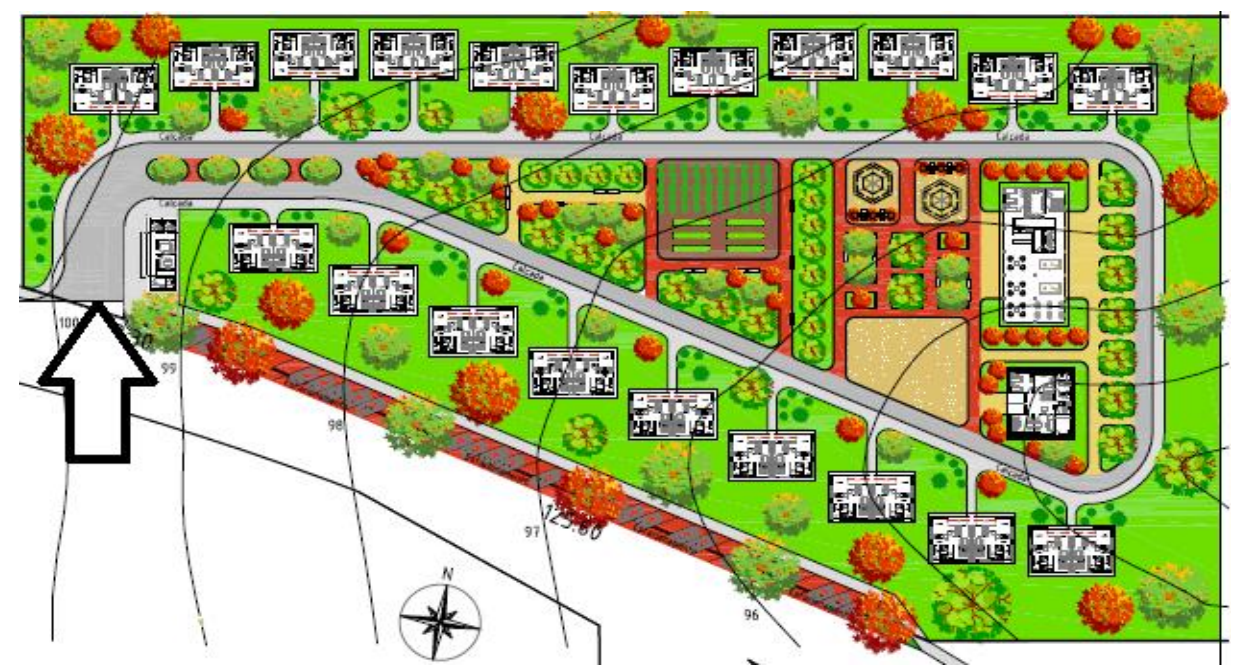

Fonte: Plantas fornecidas pela CEHAP (2015). 
Diferentemente de Leung et al. (2019), o presente estudo é de cunho qualitativo e mesmo usando um questionário como os autores utilizaram foi possível apresentar dados mais ricos quanto à caracterização dos idosos e às informações técnicas/dimensionais do complexo habitacional, opção que corrobora indicação de Rodrigues e Imai (2019).

O Cidade Madura, localizado no bairro de Cidade Verde, zona sul da cidade de João Pessoa, possui 40 unidades residenciais planejadas para pessoas idosas, com ou sem necessidades especiais, onde cada edificação é composta por duas casas geminadas. O Habitacional ainda conta com uma praça; uma horta comunitária; um espaço de convivência; uma pista de caminhada; um posto médico; um estacionamento; uma área destinada a redes de descanso (redário); uma guarita e uma administração (PB AGORA, 2014).

Um aspecto a ser considerado é que programas como esse, cujo objetivo é prover acesso à moradia para idosos de baixa renda, facilitado por órgãos públicos, podem ser encontrados no Brasil e internacionalmente (LUCREDI, 2019). Nessa direção, há necessidade de entendimento do processo de envelhecimento e a adoção de estratégias da pessoa idosa para a iniciativa do aging in place (COSTA et al., 2015), bem como a compreensão de características sociodemográficas do público-alvo (TESTON et al., 2015).

No contexto brasileiro, até o momento da pesquisa o Cidade Madura apresenta-se como o único construído segundo parâmetros de acessibilidade e direcionado exclusivamente para idosos independentes. Para obtenção dos dados foram adotadas as ferramentas de pesquisa: questionário semi estruturado e composto por duas partes, sendo a primeira relativa ao perfil socioeconômico do idoso, apresentando sete questões fechadas e a segunda para coleta da opinião do idoso-morador do habitacional; checklist para verificação das dimensões dos espaços das unidades; avaliação de mobilidade nas unidades pesquisadas utilizando modelos antropométricos em planta baixa.

A aplicação do questionário foi realizada com idosos residentes a partir de amostra intencional, contemplando indivíduos de ambos os sexos, sem distinção de grau de escolaridade, nem estado civil. Nesse sentido, foram distribuídos 20 instrumentos de avaliação, onde para o cálculo amostral foi considerado um erro amostral de 15\%, nível de confiança de $95 \%$ e uma população de 40 indivíduos (COMENTTO, 2015). Além da observação in loco dos espaços do Habitacional. Os achados da pesquisa foram analisados sob três aspectos: legislação projetual para construção do empreendimento, norma de acessibilidade (elemento norteador do projeto) e literatura específica ao tema abordado.

Devido ao fato de não haver regulamentação específica de parâmetros dimensionais para projetos dessa natureza e por se tratar de residências, a avaliação com o checklist foi realizada objetivando verificar 0 atendimento ao Código de Obras de João Pessoa (JOÃO PESSOA, 1971), promulgado pela Lei oㅜ 1. 347 de 27 de abril de 1971, onde há orientações sobre o dimensionamento dos espaços da habitação e do uso do solo. Além disso foi investigado se houve a correta aplicação das normas de acessibilidade vigentes à época da pesquisa - ABNT NBR 9050, nos ambientes do posto médico e das casas.

Visando avaliar o uso do ambiente no desempenho das atividades para os espaços projetados, foram utilizados modelos antropométricos que contemplam zona de conforto pessoal e de circulação (PANERO; ZELNIK, 2013), assim identificando as condições de uso favoráveis ou não para as funções desenvolvidas. Desse modo, os espaços foram analisados segundo os modelos antropométricos representativos para as condições de adequação (realçado em verde), de restrição (realçado em amarelo) e inadequação (realçado em vermelho).

Como mencionado, apenas o uso de um único instrumento metodológico pode não trazer as informações completas sobre a pesquisa. Portanto, o uso em conjuntos de técnicas é importante para captar ao máximo as informações da pessoa entrevistada. Esse fato foi constatado por Rodrigues e Imai (2019), que mostraram que apenas a entrevista poderia não trazer os dados necessários para montar as diretrizes habitacionais desejáveis pelos idosos. Portanto, os autores incorporaram um modelo de simulação tridimensional em que o idoso poderia movimentar, inserir e adicionar itens a seu gosto, construindo seu espaço ideal. A pesquisa foi aprovada pelo Comitê de Ética em Pesquisa da Universidade Federal sob o número do CAAE 40768315.0.0000.5208.

Os resultados obtidos com as avaliações são apresentados em blocos que revelam a caracterização dos sujeitos da amostra, a análise obtida através do checklist de verificação de normas, a opinião dos idosos trazendo a voz do usuário para a avaliação, e, a análise do ambiente em uso que auxilia no entendimento da mobilidade no espaço e identifica suas inadequações.

\section{Identificação do público alvo}

O perfil socioeconômico dos idosos foi identificado com base nas informações coletadas a partir de 
questionários aplicados. No tópico gênero houve leve predominância do sexo feminino, com 11 mulheres e 9 homens. Quanto à faixa etária, a predominância foi entre 60 anos e 80 anos (8 idosos entre 60 a 70 anos, 8 entre 71 a 80 anos), havendo apenas 4 idosos acima dos 80 anos. Quanto ao estado civil, verificou-se predominância dos viúvos (8), além de 3 solteiras, 7 casados e 2 separados. No que diz respeito à renda financeira, a maioria dos respondentes afirmou receber 1 salário mínimo (17 moradores), 2 moradores recebem 2 salários mínimo e apenas uma moradora afirmou não ter nenhum tipo de rendimento. No nível educacional, os dados evidenciaram 3 moradoras sem instrução - analfabetas, 4 com instrução em nível fundamental incompleto, 6 de nível fundamental completo, 2 com nível médio incompleto e 4 de nível médio completo e 1 morador de nível superior. Quanto ao item religião, a crença católica (12 moradores) foi a mais presente, seguida pelas crenças evangélica (6 moradores), adventista (1 morador) e espírita (1 moradora).

Neste conjunto de informações cabe ainda acrescentar que todos os idosos residentes no Cidade Madura são independentes, sendo esta uma condição para que serem contemplados com uma das casas, embora se registre que ao longo do tempo alguns passam a precisar de auxílio nas tarefas cotidianas, o que demanda ter mais uma pessoa em casa.

\section{Análise pelo Checklist}

Os dados deste tópico apoiam-se na aplicação do checklist elaborado com base no Código de Obras de João Pessoa (JOÃO PESSOA, 1971) e normas de acessibilidade da NBR 9050. A avaliação do uso espacial foi realizada a partir das plantas baixas disponibilizadas pela Companhia Estadual de Habitacional Popular CEHAP (responsável pela construção do habitacional), somada à observação no local. As unidades focadas nesta análise foram as residências e o Posto Médico.

De acordo com os registros gráficos cedidos pela CEHAP para as unidades habitacionais (Figuras 2 e 3), bem como por observações dirigidas in loco, observou-se:

- Casas compostas por 6 (seis) ambientes: terraço, sala, quarto, banheiro, cozinha e área de serviço;

- Tipologia adequada aos seus usuários (para a quantidade e tipo de ambientes propostos);

- Rampa de aceso à residência dotada de corrimão;

- Terraço - peitoril em alvenaria com altura de 1,10 m;

- Mobiliário e decoração - definidos e adquiridos pelos residentes (embora a cehap tenha desenvolvido uma possibilidade de layout quando da elaboração do projeto);

- Sala permite acomodar minimamente os móveis necessários;

- Quarto - dimensões reduzidas notadamente se considerada a ocupação por dois moradores;

- Cozinha - pouco espaçosa, não possibilitando o trabalho sentado, contudo é ventilada e iluminada;

- Banheiro - amplo e possui banco no box do chuveiro, além de barras de segurança adequadamente instaladas;

- Lavanderia - espaço bem reduzido.

Ressalva-se o uso do Código de Obras de João Pessoa como parâmetro de avaliação do conjunto habitacional, por ser este um programa público que deve estar em consonância com as normas legais de construção da cidade. Contudo, não foram localizadas referências bibliográficas que envolvam este tema e usem tal Código como base para a investigação. Por outro lado, o conjunto Cidade Madura foi idealizado e construído à luz da acessibilidade para pessoas idosas, entretanto, observou-se que alguns ambientes da unidade habitacional não permitem a mobilidade plena de usuário em cadeira de rodas, repetindo-se alguns dos resultados obtidos por Yoshida e Magagnin (2016), entre os quais destacam-se:

- Com relação ao tamanho da sala de estar/jantar, os idosos entrevistados afirmaram que poderia ser menor para que o quarto fosse mais amplo, e permitir uma movimentação mais fácil.

- Sobre a iluminação natural, os cômodos da casa apresentaram-se com iluminação deficiente, o que pode propiciar riscos acidentários aos idosos. A área de serviço, por exemplo, é dotada de elementos vazados (cobogós) em toda a extensão da parede externa, acarretando pouca luminosidade durante o dia. Quanto à ventilação, as aberturas existentes nos ambientes atendem às normas vigentes.

- Relativamente ao espaço da cozinha, as janelas apresentam venezianas em madeira com pintura, permitindo a ventilação quando fechadas, porém a iluminação se apresenta deficitária. $O$ fechamento das janelas também é inadequado, pois é feito através de fecho simples localizado à meia altura, o que exige mais força para seu manuseio e dificulta a pega pela localização e caracterização do dispositivo. 
Figura 2: Unidade habitacional - Acesso ao terraço, sala e quarto.
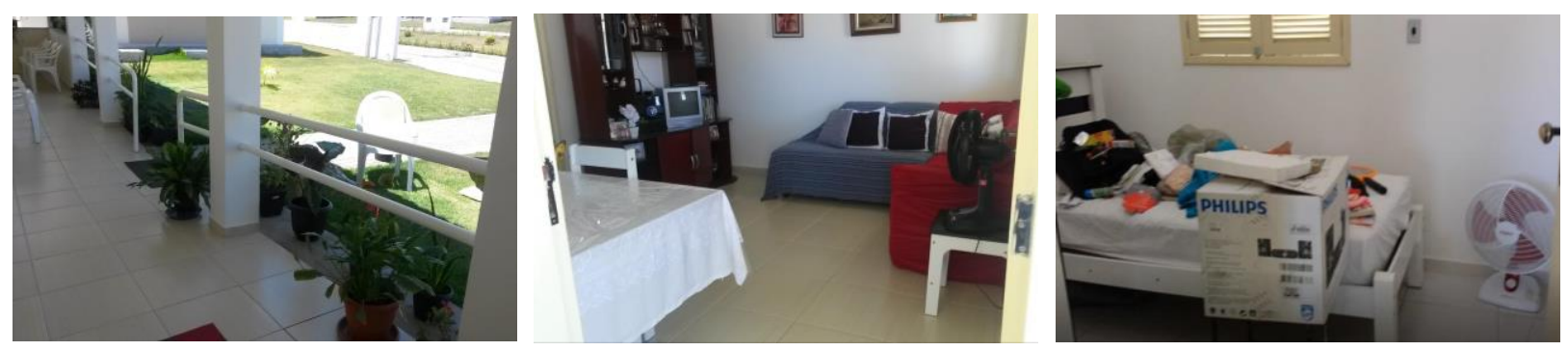

Fonte: Autores.

Figura 3: Unidade habitacional - Banheiro, cozinha, e área de serviço.
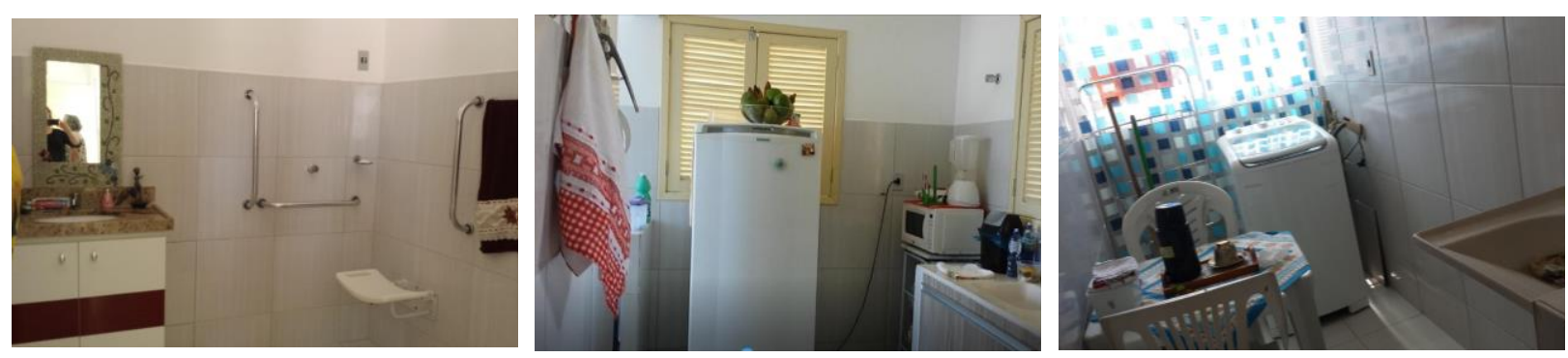

Fonte: Autores.

A Tabela 1, a seguir, apresenta os aspectos legais preconizados pela legislação do Código de Obras de João Pessoa (JOÃO PESSOA, 1971) para os ambientes das unidades residenciais analisadas e o atendimento ou não a essas exigências, considerando a avaliação espacial e observações in loco.

Diante dos achados referentes às unidades habitacionais, muitos dados são corroborados pelo estudo de Yoshida e Magagnin (2016), à exceção do aspecto dimensional do ambiente da cozinha que no habitacional apresentou concordância com o preconizado em legislação.

Tabela 1: Análise dos aspectos legais para unidades residenciais, segundo o Código de Obras de João Pessoa.

\begin{tabular}{|c|c|c|c|c|c|}
\hline AMBIENTE & ÁREA & $\begin{array}{l}\text { ÁREA } \\
\text { MÍNIMA }\end{array}$ & $\begin{array}{l}\text { RESPALDO } \\
\text { LEGAL }\end{array}$ & EXIGÊNCIA & CONDIÇÃO \\
\hline \multirow[b]{2}{*}{ QUARTO } & \multirow[b]{2}{*}{$7,00 \mathrm{~m}^{2}$} & \multirow[b]{2}{*}{$8,00 \mathrm{~m}^{2}$} & \multirow[b]{2}{*}{ Art. $168 \S 2$} & Circunscrição círculo com raio $\geq 1,30 \mathrm{~m}$ & NÃO ATENDE \\
\hline & & & & $\begin{array}{c}\text { Aberturas exteriores com venezianas ou } \\
\text { outro dispositivo }\end{array}$ & ATENDE \\
\hline \multirow{2}{*}{$\begin{array}{l}\text { SALA } \\
\text { ESTAR/JANTAR }\end{array}$} & \multirow{2}{*}{$13,28 \mathrm{~m}^{2}$} & \multirow{2}{*}{$8,00 \mathrm{~m}^{2}$} & \multirow{2}{*}{ Art. 168} & Circunscrição círculo com raio $\geq 1,30 \mathrm{~m}$ & ATENDE \\
\hline & & & & $\begin{array}{l}\text { Aberturas exteriores com venezianas ou } \\
\text { outro dispositivo }\end{array}$ & ATENDE \\
\hline \multirow{6}{*}{ COZINHA } & \multirow{6}{*}{$4,68 \mathrm{~m}^{2}$} & \multirow{6}{*}{$4,00 \mathrm{~m}^{2}$} & \multirow{6}{*}{$\begin{array}{l}\text { Art. 170; } \\
\text { Art. } 172\end{array}$} & Circunscrição círculo com raio $\geq 0,80 \mathrm{~m}$ & ATENDE \\
\hline & & & & $\begin{array}{c}\text { Localização - sem comunicação direto com } \\
\text { quarto ou banheiro }\end{array}$ & ATENDE \\
\hline & & & & $\begin{array}{c}\text { Aberturas exteriores com venezianas ou } \\
\text { outro dispositivo }\end{array}$ & PARCIAL \\
\hline & & & & Pé direito $\geq 2,60 \mathrm{~m}$ & ATENDE \\
\hline & & & & Forro - material incombustível & ATENDE \\
\hline & & & & Piso antiderrapante e dotado de ralo & NÃO ATENDE \\
\hline \multirow{3}{*}{ BANHEIRO } & \multirow{3}{*}{$5,75 \mathrm{~m}^{2}$} & \multirow{3}{*}{$3,00 \mathrm{~m}^{2}$} & \multirow{3}{*}{$\begin{array}{l}\text { Art. } 175 \S 1 \\
\text { e } \S 2\end{array}$} & Circunscrição círculo com raio $\geq 1,30 \mathrm{~m}$ & ATENDE \\
\hline & & & & Box chuveiro $\geq 0,80 \times 0,80 \mathrm{~m}$ & ATENDE \\
\hline & & & & Piso antiderrapante e dotado de ralo & NÃO ATENDE \\
\hline
\end{tabular}

Fonte: Autores. 
No que diz respeito aos espaços da moradia foi identificada a associação dos ambientes internos à qualidade de vida dos usuários idosos, no tocante ao dimensionamento, condicionantes físicos e conforto ambiental. Também se coloca a questão de adequação do mobiliário ao espaço físico disponível, que repercute diretamente na acessibilidade. Diante dessa questão do mobiliário, Leung et al. (2019) colocam a necessidade de considerar a antropometria do usuário idoso ao mobiliário.

De acordo com informações do setor de projetos da CEHAP, o WC foi concebido e construído segundo a NBR 9050 (ABNT, 2004). A área física do ambiente é compatível com a legislação, além de contemplar equipamento de segurança e critérios de acessibilidade - dispõe de área de transferência de cadeira de rodas tanto para a bacia sanitária quanto para o box do chuveiro, validando o requerido pelo Código de Obras. $\mathrm{O}$ local reservado ao chuveiro atende às dimensões mínimas estabelecidas na NBR 9050, porém revela um pequeno desnível para escoamento da água para o ralo. Quanto aos metais sanitários, identificou-se que as torneiras não são do tipo alavanca.

Verifica-se ainda que há instalado no box do chuveiro um banco com dimensões de 0,70 $\mathrm{m} \times 0,45 \mathrm{~m}$, com cantos arredondados, de superfície antiderrapante e impermeável, conforme prevê a norma de Acessibilidade da ABNT. A ducha apresenta altura maior que $1,00 \mathrm{~m}$, bem como a saboneteira e o porta-toalhas estando todos em altura acima do recomendado em legislação.

Para o ambiente de área de serviço a NBR 15.575 (ABNT, 2013) estabelece que este espaço tem que dispor de tanque (externo para unidades habitacionais térreas) e máquina de lavar roupa. Apesar de ser uma casa térrea foi verificada in loco a inexistência de abertura da área de serviço para a área externa; sendo um espaço muito reduzido o tanque está localizado em posição desfavorável à promoção de um arranjo físico mais adequado.

Rieh (2018) investigou habitações públicas para idosos na Coreia e concluiu a importância da flexibilização do espaço de moradia para os usuários idosos, adequando o uso espacial de acordo com as necessidades dos usuários residentes. Não menos importante foi a conclusão de que para a segurança do idoso a acessibilidade no espaço da habitação é primordial, havendo que considerar também a presença de um cuidador para as situações que assim exijam.

Além da unidade habitacional foi avaliado o Posto Médico (Figura 4), que se mostrou um ambiente frequentado pelos residentes do habitacional, embora se verifique baixa procura do serviço oferecido.

Figura 4: Posto Médico - Banheiro, cozinha, e área de serviço.


Fonte: Autores.

Não tendo sido encontradas normas específicas para este tipo de equipamento dentro de condomínios, verificou-se a adequação à NBR 9050 (norma de acessibilidade) e foram percebidas algumas inadequações:

- Piso tátil - Não identificado, conforme rege a legislação NBR 9050. Esta inadequação se estende a todo o complexo habitacional;

- Elementos sinalizadores para pessoas com deficiência visual - Não identificado;

- Acesso à edificação do Posto Médico - está em rota acessível, contudo se localiza longe da saída do condomínio;

- Rebaixamentos das calçadas - Existente, porém localizados em lados opostos da via lateral (não se encontram alinhados entre si, acarretando quebra na rota);

- Sanitários - Conformidade com a demanda registrada no momento da investigação. Entretanto, não satisfaz à necessidade emergencial do aumento da procura de atendimento (Figura 4);

- Mobiliário existente (maca, cadeira de rodas, entre outros) - Conformidade com a necessidade registrada no momento da investigação; 
- Portas dos ambientes de salas - Em acordo com a legislação (vão livre de 0,80m);

- Esquadria de acesso à edificação - Porta dupla (com 0,80m cada) e folhas fixas. Contudo, o giro de abertura das portas compromete o acesso aos dois primeiros ambientes do Posto Médico (Consultório odontológico e Enfermaria), ocasionando dificuldade para adentrar nessas salas.

Apesar dos vãos livres da porta atenderem ao parâmetro estabelecido na legislação $(0,80 \mathrm{~m})$, observou-se que uma dimensão maior seria mais confortável para a condução de uma cadeira de rodas em segurança

Assim como na unidade habitacional, a análise do Posto Médico também evidenciou alguns parâmetros em desacordo com as diretrizes do Código de Obras (JOÃO PESSOA, 1971), bem como divergências relacionadas às exigências da NBR 9050 (ABNT, 2004). Tais condições foram identificadas também por Yoshida e Magagnin (2016) ao constatar o não cumprimento integral das normas técnicas vigentes. Além desta avaliação sob o foco das normas, a usabilidade é tratada no tópico do ambiente em uso.

\section{Opinião do Idoso-morador}

Destaca-se que é vedado aos moradores do Condomínio Cidade Madura fazer qualquer tipo de alteração na habitação. No entanto, a investigação apontou relatos dos idosos expressando a necessidade de adequações em alguns ambientes.

Dos questionários aplicados, 6 homens e 8 mulheres expressaram o desejo de executar algum tipo de reforma na casa, sendo prioritário o desejo de aumentar a área da cozinha e colocar grade de proteção na porta. Foram citados também: (i) construir um outro quarto (3 moradoras e 1 morador); (ii) abrir uma porta na área de serviço permitindo o acesso à área externa, além de criar uma saída de emergência em caso de necessidade (1 moradora e 3 moradores).

$\mathrm{Na}$ casa o ambiente preferido dos idosos foi a sala (2 moradores), seguido pelo ambiente de quarto (2 moradores) e do terraço (2 moradores). A casa propriamente dita foi citada por 5 idosos (2 moradores e 3 moradoras) e a horta por apenas um deles. Já para o ambiente de sala, 5 moradoras afirmaram ser o local preferido na moradia. O quarto, o terraço e a cozinha foram ambientes apontados como o ambiente preferido, por apenas 1 moradora, para cada um dos espaços citados.-Assim, entre as mulheres, evidencia-se a escolha pela sala, lugar que é amplo, com boa iluminação natural e onde se encontra a televisão.

Quanto ao revestimento do piso, foi registrado ser bom em todos os espaços da casa (sala, quarto, banheiro, cozinha e lavanderia), segundo a opinião dos usuários. Mas, como relatado na sessão anterior, ao ser molhado, o piso se torna escorregadio.

Três residentes ( 1 idosa e 2 idosos) relataram que as portas e janelas não permitem bom manuseio (maçaneta e material ruim) e nem há espaço adequado para abertura da porta. Por sua vez, duas idosas relataram que esses dispositivos no quarto e na cozinha não são fáceis de manipular, e que na cozinha e na sala eles não possuem altura adequada.

A cozinha foi considerada boa pelos residentes e com espaço suficiente para aberturas de portas dos equipamentos e mobiliário (geladeira, forno e gavetas), para trabalhar sentado e para guardar e alcançar materiais de uso e boa altura da pia (por 5 idosas e 6 idosos). Os outros 9 residentes pesquisados apontaram algumas inadequações, como: não conseguir trabalhar sentado, por que o espaço físico da cozinha é pequeno ( 5 idosas e 4 idosos); área insuficiente para guardar e alcançar os materiais de uso na cozinha (1 idosa e 2 idosos); e pouco espaço para aberturas de gavetas ( 1 idosa e 2 idosos).

No banheiro, o arranjo físico foi considerado seguro, amplo e conveniente, assim como a altura do vaso sanitário, os cabides para pendurar as toalhas e a papeleira. Os registros e torneiras são fáceis de manipular, a barra de apoio é segura, não arranha e tem altura boa para 19 dos respondentes e apenas uma pessoa afirmou que os registros e torneiras não são fáceis de manipular, sendo necessário outra forma para abrir.

Resgata-se aqui a sugestão de Cambiaghi (2014), ao indicar que, a fim de favorecer a movimentação das pessoas, a área de circulação de uma cozinha deve ser $1,20 \mathrm{~m} \times 1,50 \mathrm{~m}$ e livre de qualquer obstáculo. Identifica-se que na cozinha avaliada não foram registradas tais dimensões, não permitindo a distribuição de mobiliário mínimo estabelecida.

Os resultados dos questionários aplicados aos idosos ressaltam ainda ser necessário um estudo pormenorizado na disposição das áreas de convivência do habitacional, afim de intensificar a frequência do uso dos espaços comuns, como aquele destinado à horta comunitária e ao redário, propiciando, assim, a otimização da convivência social entre moradores. A locação dos equipamentos de convivência comunitária em residenciais se constitui aspecto de relevância em sua acessibilidade e uso, uma vez que o processo de envelhecimento inexoravelmente concorre para alterações de ordem fisiológica, sensório-motor e cognitiva, 
repercutindo na interação entre os moradores idosos e em sua qualidade de vida.

Diante das colocações da voz do usuário, observa-se que os espaços físicos do habitacional Cidade Madura necessitam de reavaliação para futuros projetos, a fim de proporcionar melhoria do conforto, segurança e satisfação dos moradores idosos. Nesse caso se mostra pertinente a sugestão de Rodrigues e Imai (2019), cuja investigação constatou que, a partir de um modelo de simulação física tridimensional (maquete física), os idosos puderam demonstrar um "conjunto de necessidades ou idealizações para um apartamento mais próximo à sua realidade". Além disso, o fato de existir uma necessidade de proposição de diretrizes projetuais para o Habitacional, corrobora as preocupações de Lucredi (2019), ao constatar as perdas naturais do idoso, principalmente quanto ao aspecto da mobilidade do idoso na casa.

\section{Análise do ambiente de uso}

As moradias do conjunto habitacional Cidade Madura estão dispostas de ambos os lados de uma via interna do conjunto e são compostas por grupos de duas unidades habitacionais (casa geminada), guardando afastamento com relação às edificações laterais. Devido a essa implantação, as unidades habitacionais têm orientação Norte ou Sul, a depender de sua localização. A unidade habitacional dispõe de ambientes com bom dimensionamento, à exceção do espaço do quarto, apesar do layout para o restante dos cômodos apresentar situações de inadequação de circulação na sala e na área de serviço.

Relativamente ao arranjo dos móveis, devido à variedade de mobiliário registrada nas unidades habitacionais visitadas, a investigação admitiu como padrão o layout proposto em projeto pela CEHAP.

Assim, para a análise do ambiente no desenvolvimento das atividades foram adotados módulos antropométricos representativos de figura humana na posição em pé em deslocamento, na posição em pé trabalhando e na posição sentado, para as situações de adequação, destacados na cor verde, para as situações com restrição, destacados pela cor amarela e para situações de inadequação, destacados na cor vermelha, como apresenta a Figura 5.

Figura 5: Unidade habitacional - Planta Baixa e Layout.

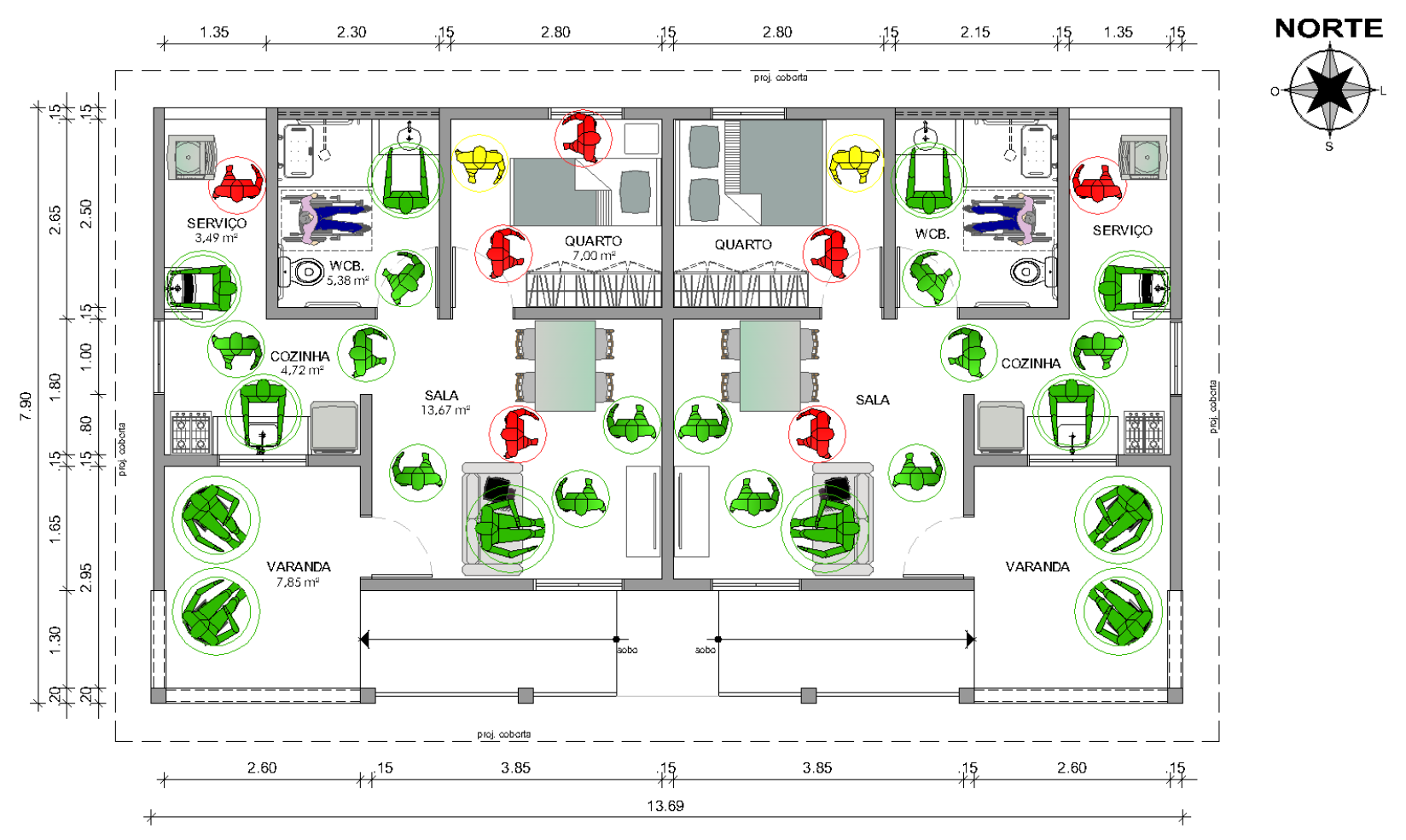

Fonte: Adaptado de plantas fornecidas pela CEHAP.

O espaço é exíguo para acomodar as demandas do usuário no ambiente, seja com ocupação para um (Figura 6a) ou dois (Figura 6b) idosos, implicando em layout com restrição e inadequação de circulação, comprometendo o desenvolvimento satisfatório das atividades e concorrendo para riscos acidentários. 
Figura 6a e 6b: Unidade habitacional - Quarto para 1 idoso e quarto para casal.
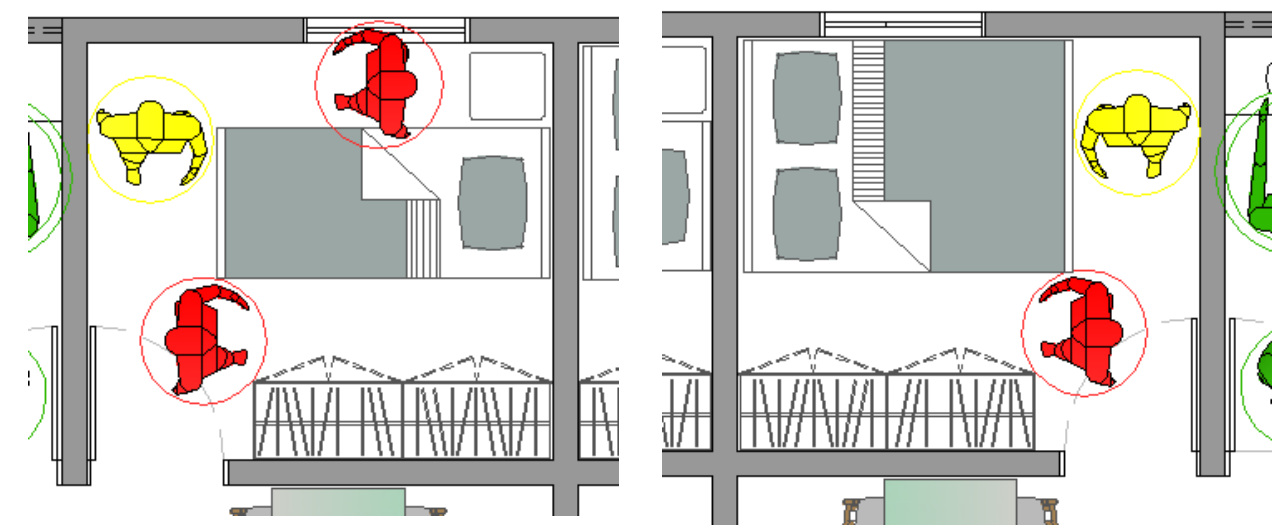

Fonte: Adaptado de plantas fornecidas pela CEHAP.

Observa-se que no caso da composição para um só ocupante, ou seja, cama de solteiro, existe restrição em atingir ambos os lados da cama. Tal necessidade para o uso do espaço com uma cama de casal se torna inapropriado, pois o móvel tem que se posicionar junto à parede, impedindo o acesso por um dos lados, e ainda tendo o acesso pelo outro lado da cama comprometido, pois o espaço resultante entre a cama e o guarda-roupa não é adequado. Já o espaço destinado ao banheiro encontra-se em adequação para a movimentação, seja por pessoa cadeirante ou não.

De acordo com os modelos antropométricos demonstrados na Figura 3, o layout de sala proposto pela CEHAP para as moradias e aqueles identificados in loco indicam adequação da distribuição do mobiliário às funções previstas para o ambiente, não havendo interferências de equipamentos ou mobiliário no desenvolvimento das tarefas ali desenvolvidas. Contudo, foi observada uma restrição de passagem entre a mesa e o sofá, que pode ser adequada com nova composição para os móveis.

Também no ambiente da área de serviço proposto pela CEHAP (2012) verifica-se uma restrição de movimentação na altura da localização da máquina de lavar roupa, que em muitas das casas visitadas encontra-se em disposição diferente, a fim de facilitar a execução das tarefas.

Desta avaliação verificam-se inadequações em relação à norma NBR 15.575 (2013) que recomenda que: (i) o quarto tem que poder acomodar, no mínimo, uma cama de casal, um guarda roupa e um criado-mudo; (ii) a cozinha tem que ter espaço suficiente para um fogão, uma geladeira, pia de cozinha, um armário sobre a pia, um gabinete e um apoio para refeição - ao menos para duas pessoas (ABNT, 2013).

Assim como na análise da Unidade habitacional, no Posto Médico (Figura 7). Foram utilizados os modelos antropométricos que simulam a movimentação de pessoas seja andando, sentadas ou trabalhando em pé. A avaliação espacial nessa edificação revelou que os ambientes de banheiro público e de serviço, repouso, copa/cozinha e depósito permitem uma acessibilidade favorável e sem impedimento de barreiras físicas ao desenvolvimento das atividades previstas para cada um desses espaços físicos, apenas com ressalva para o banheiro de serviço onde foi identificada restrição de acesso e para o ambiente de depósito para uso do tanque que se localiza muito próximo à parede.

Contudo, no ambiente de recepção, apesar do dimensionamento ser favorável, a distribuição das cadeiras em formato longarina apresenta espaçamento pequeno entre assentos, evidenciando uma restrição de uso de pessoas lado a lado. Também nesse ambiente observa-se que a circulação fica deficitária para o uso concomitante de cadeirante e pessoa sentada na longarina.

O arranjo espacial apresentado para o consultório médico indica restrições para a utilização simultânea de assento para acompanhante de consulta, assim como de assento para o médico e o uso de lavatório para assepsia. Para o consultório odontológico a restrição observada se limita ao assento de acompanhante simultâneo com o paciente. 


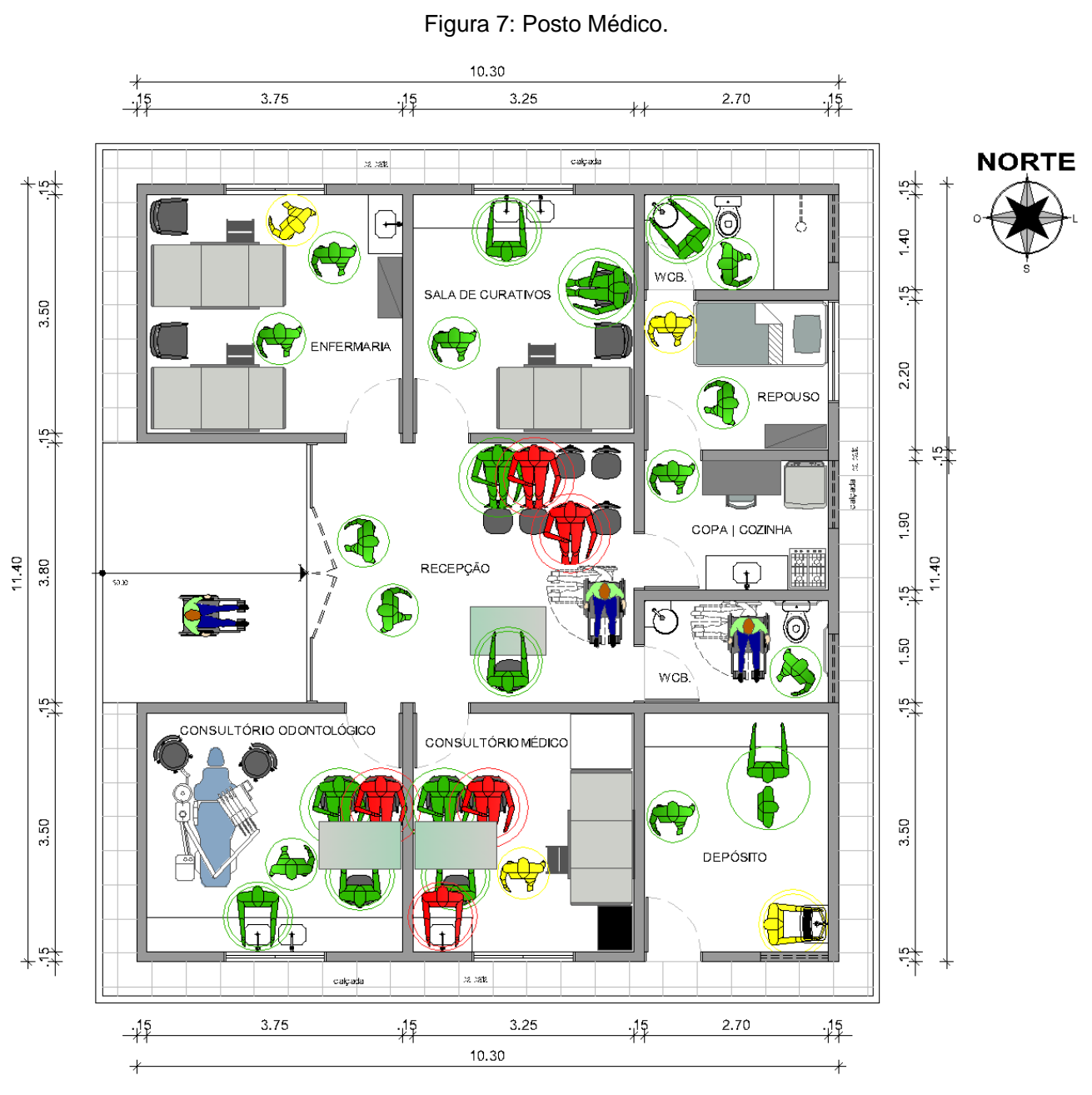

Fonte: Adaptado de plantas fornecidas pela CEHAP.

\section{Observações gerais}

A proposta da construção desse habitacional como o primeiro de outros que vem sendo realizados em outras cidades paraibanas, é uma iniciativa que visa suprir a ausência de moradia para a população idosa. Mesmo diante da grande dificuldade de atender a demanda existente com uma população que envelhece, o empreendimento se apresenta como um importante passo na direção do que se coloca: "a garantia do direito a cidades sustentáveis, entendido como o direito à terra urbana, à moradia, ao saneamento ambiental, à infraestrutura urbana, ao transporte e aos serviços públicos, ao trabalho e ao lazer, para as presentes e futuras gerações" ( JOÃO PESSOA, 2001, art. 2).

Embora o Conjunto Cidade Madura seja apontado como modelo e inspire programas semelhantes em outros estados (PARAÍBA, 2019), a realização desta pesquisa identificou problemas que se inserem na falta de cumprimento de legislações próprias, no subdimensionamento de ambientes e na existência de necessidades dos habitantes não atendidas. Além disso, as demandas por ajustes identificadas dificilmente serão solucionadas pelos moradores, visto que as casas não podem passar por mudanças físicas/estruturais em função da proibição nas normas da administração (incluídas inclusive na seleção dos participantes), imposição que soma-se ao reduzido poder aquisitivo do grupo.

Observado sob o prisma das legislações, do olhar do usuário e da usabilidade dos espaços, onde são registradas importantes necessidades de melhorias, é possível identificar o sentimento de satisfação dos usuários por ter uma moradia. Contudo, há problemas que poderiam ter sido evitados na concepção do projeto, se adotado critérios de ergonomia, incluindo a acessibilidade. De modo semelhante ao encontrado por Rodrigues et al. (2020), ficou evidente que as normas sobre acessibilidade vigentes foram seguidas em parte, mas que, como apontam os autores, o ambiente habitacional necessita de condições que possam estimular o idoso a vivenciar os espaços de forma prazerosa e autônoma (habitabilidade).

O dimensionamento de ambientes como o quarto, não se insere sequer nas dimensões mínimas prescritas 
pelo código de obras da cidade, gerando questões de usabilidade, como descrito no tópico de análise do ambiente em uso. Problemas como a falta de acesso da área de serviço ao exterior da casa, a dificuldade de deslocamento em cadeira de rodas devido ao subdimensionamento, entre outros itens apontados neste estudo, fragiliza a qualidade do espaço para a população à qual se destina. Tais constatações são agravadas ao verificar-se a existência de área de terreno disponível, conforme se mostra na Figura 8.

Figura 8: Área do empreendimento.

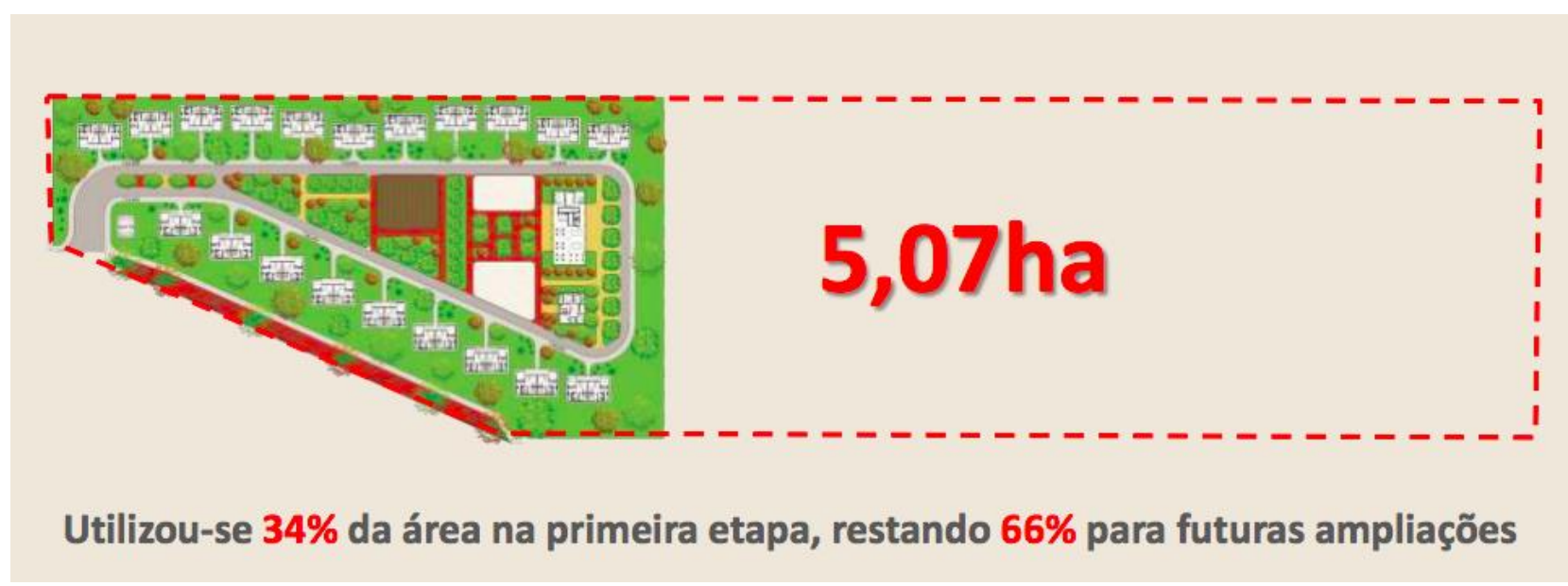

Fonte: Lima (2015).

Sobre a acessibilidade no Habitacional, destaca-se como fundamental a percepção e entendimento dos moradores, assim como a qualidade espacial para a segurança dos usuários, mas especificamente da pessoa idosa que lá reside. Dessa maneira, se faz necessária a segurança integral dos ambientes físicos com a existência de vários aspectos, tais como: pisos antiderrapantes, dimensionamento e inclinação de rampas dotadas de corrimão, vagas de estacionamento dimensionadas e demarcadas corretamente, maçanetas, alavancas e fechos de portas e janelas com pegas ajustadas ao processo de envelhecimento, sinalização legível com atenção a cores e contrastes, altura de comandos, interruptores e tomadas elétricas, entre tantos outros elementos, todos adequados à legislação vigente em busca de eliminar ou ao menos mitigar as barreiras físicas impeditivas ao bom funcionamento espacial.

A partir das análises realizadas é possível inferir que com pouca variação orçamentária podem ser viabilizados os ajustes necessários, principalmente nas unidades habitacionais. Ademais, acontecimentos recentes fizeram com que os olhares se voltassem à habitação, à necessidade de espaços bem dimensionados e com boa usabilidade. No atual momento que se vive neste ano de 2020, quando a pandemia provocada pelo Coronavírus tem promovido a necessidade de uso mais intenso dos espaços residenciais, são exacerbadas as dificuldades e problemas do uso da moradia. Embora no caso em estudo se trate de pessoas idosas, que provavelmente não demandam espaços para desenvolvimento de atividades laborais, há de se pensar sobre a longa permanência desta população em espaços exíguos como os encontrados neste empreendimento.

Mesmo considerando que o condomínio dispõe de áreas de uso coletivo, considera-se que a necessidade de distanciamento pessoal e a indicação de permanecer em casa, impede a vivência nesses espaços onde a praça é o mais utilizado no presente estudo. De fato, a avaliação dimensional, dos critérios de acessibilidade e da usabilidade dos ambientes deve surgir como forte preocupação nos novos empreendimentos residenciais. Neste contexto, sabe-se que as barreiras da relação conforto x lucro do empreendimento surgirão com forte apelo no mercado imobiliário. No caso dos empreendimentos assistenciais, como o tratado neste estudo, emerge a necessidade de sensibilização dos provedores, da equipe de projeto aos decisores em níveis financeiros, administrativos e políticos. Mesmo tratando de um público específico, certamente o Condomínio Cidade Madura e similares se inserem nas políticas de provisão de moradia às camadas mais necessitadas da sociedade.

\section{CONSIDERAÇÕES FINAIS}

O objeto de estudo - Condominio Cidade Madura - é um habitacional projetado pela esfera pública e destinado especificamente às pessoas idosas independentes, autônomas e com perfil econômico de baixa renda, tendo a acessibilidade plena como elemento projetual norteador. 
Os achados identificados no presente estudo foram analisados à luz da literatura investigada na temática da pessoa idosa, mais precisamente no tocante ao morar sozinho. Diante disso, foram observados resultados que trazem preocupações que direcionam à necessidade de um olhar conceitual diferenciado aos projetos destinados às pessoas idosas. É imperativo buscar garantir a segurança e o dimensionamento apropriado aos ambientes residenciais, a criação de possibilidades de adequado layout à demanda por mais conforto e segurança nas casas, além de cuidados no atendimento às exigências de normas e legislações.

As questões dimensionais relativas aos ambientes analisados do conjunto habitacional Cidade Madura unidade habitacional e Posto Médico, objetos do presente estudo - evidenciaram necessidade de adequação espacial ao desenvolvimento de atividades de vida diária ali praticadas pelos moradores idosos.

Entendendo ser acelerado o crescimento da população idosa, não só a nível mundial como também no Brasil, e o crescente aumento da expectativa de vida, é legítima a preocupação com a adequação espacial de habitações, para a promoção do envelhecimento bem-sucedido e da melhoria da qualidade de vida e bemestar de pessoas idosas em suas moradias. Contudo, nem só a aspectos legais esses espaços estão vinculados, mas também a dimensões simbólicas e afetivas, que emergem em representações de muitos significados para cada morador, intensificando o sentido de identidade e pertencimento.

Deve ser assegurada por meio do projeto uma maior autonomia e qualidade de vida aos idosos, permitindo desfrutar melhor dos seus ambientes. Considerar a opinião dos idosos no momento do projeto ou até mesmo em uma avaliação pós-ocupação é fundamental para suprir seus anseios e proporcionar ainda mais conforto e satisfação. Além disso, não só o atendimento a legislações deve ser considerado, mas também, a adoção de critérios ergonômicos na projetação, conferindo um olhar sistêmico sobre o ambiente, sua utilização e a percepção do usuário.

Assim, considerando que a maioria dos idosos deste tipo de empreendimento são independentes e realizam atividades diárias domésticas, é necessário um olhar ainda mais cuidadoso quanto ao quarto e à cozinha, lugares onde os idosos passam boa parte do tempo, de forma a minimizar, por exemplo, as necessidades de ajustes e ampliações, que se destacaram dentre os desejos de alterações a serem realizadas no conjunto habitacional em João Pessoa.

\section{REFERÊNCIAS}

ASSOCIAÇÃO BRASILEIRA DE NORMAS TÉCNICAS (ABNT). NBR 9.050: Acessibilidade a edificações, mobiliários, espaços e equipamentos urbanos. Rio de Janeiro, 2004.

NBR 15.575: Edificações habitacionais - Desempenho. Rio de Janeiro, 2013.

CAMBIAGHI, S. Acessibilidade: projeto arquitetônico deve atender todo tipo de usuário. 2014. Disponível em: http://www.aecweb.com.br/cont/m/rev/acessibilidade-projeto-arquitetonico-deve-atender-todo-tipo-de-usuario_6307_0_1. Acesso em: jan. 2015.

COMENTTO. Calculadora amostral. Disponível em: https://comentto.com/calculadora-amostral/. Acesso em: jan. 2015. COMPANHIA ESTADUAL DE HABITAÇÃO POPULAR - Projeto do Residencial Cidade Madura. João Pessoa, 2012.

COSTA, F. M.; NAKATA, P. T.; MORAIS, E. P. Estratégias desenvolvidas pelos idosos residentes na comunidade para morarem sozinhos. Texto contexto - enferm, Florianópolis, v. 24, n. 3, p. 818-825, 2015.

HAZIN, M. M. V. Os espaços residenciais na percepção dos idosos. Dissertação (Mestrado). Pós-graduação em Design. Universidade Federal de Pernambuco, Recife, 2012. 143 p.

JOÃO PESSOA. Lei no 1. 347 de 27 de abril de 1971. Institui o código de obras do município de João Pessoa e dá outras providências. João Pessoa, 1971.

Lei 10.257, de 10 de julho de 2001. Trata do Estatuto da Cidade de João Pessoa. João Pessoa, 2001.

LABORDE, A. Aposentadoria feliz: idosos criam repúblicas para viver entre amigos. In: El País Internacional de 30/10/2016. Cuenca Espanha. Disponível em: https://brasil.elpais.com/brasil/2016/10/10/internacional/ 1476113070_376172.html. Acesso em: 18 de jun 2020.

LEITE, C. Cohousing: conheça um modelo de moradia compartilhada para idosos. In: Geração xMais, Seção Geral, publicado em 15/09/2019. Disponível em https://geracaoxmais.com.br/cohousing-conheca-um-modelo- de-moradiacompartilhada-para-idosos/. Acesso em: 25 de maio 2020.

LEITE, S. M. G. Morando sozinho na terceira idade - evidências empíricas sobre domicílios unipessoais de idosos de alta renda no Recife. Trabalho de Conclusão de Curso (Mestrado Profissional). Programa em Gestão Empresarial. Recife: DeVry | UniFBV, 2017.

LEUNG, M.-y., FAMAKIN, I.O., WANG, C. Developing an integrated indoor built environment-quality of life model for the 
elderly in public and subsidized housing. Engineering, Construction and Architectural Management, Vol. 26 No. 7, pp. 1498-1517. 2019.

LIMA, E. Apresentação Selo de Mérito 2015 - Cidade Madura - Cehap PB. Publicada em 8 de jul de 2015. Disponível em:https://pt.slideshare.net/associacaocohabs/emilia-correia-lima-cidade-madura. Acesso em: maio 2020.

LUCREDI, V. R. Habitação para idosos: Programa de locação social nos centros históricos de São Paulo (Brasil) e Barcelona (Espanha). Dissertação (Mestrado), Universidade Estadual de Paulista. 2019.

PAIVA, M. M. B. Ergonomia no ambiente construído de instituições para idosos - estudo de caso em instituição brasileira e portuguesa. Dissertação (Mestrado). Pós-graduação em Design. Recife: Universidade Federal de Pernambuco, 2012.

PANERO, J.; ZELNIK, M. Dimensionamento humano para espaços interiores. Barcelona: Editora Gustavo Gili. 2013.320p.

PARAÍBA. Cidade Madura serve de modelo para criação de programa habitacional no Paraná. Publicado em 11/11/2019. Disponível em: https://paraiba.pb.gov.br/noticias/cidade-madura-serve-de-modelo-para-criação- de-programahabitacional-no-parana. Acesso em 25 de maio 2020.

PASCHOAL, S. M. P. Qualidade de vida na velhice. In: FREITAS, Elizabete Viana et al. Tratado de geriatria e gerontologia. 2 ed. Rio de Janeiro: Guanabara Koogan, 2006.

PB AGORA. Programa habitacional 'Condomínio Cidade Madura' ganha destaque em revista nacional. 2014. Disponível em: http://www.pbagora.com.br/conteudo.php?id=20141113170625\&cat=paraiba\&keys=programa-habitacionalcondominio-cidade-madura-ganha-destaque-revista-nacional. Acesso em: 05 de abr 2017.

RIEH, S. Y. Post-occupancy evaluation of urban public housing in Korea: Focus on experience of elderly females in the ageing society. Indoor and Built Environment. 29(3):372-388. 2018.

RODRIGUES, R.; IMAI, C. Identificação de demandas de projeto em apartamento para usuários idosos por meio de modelos físicos. Revista Projetar - Projeto e Percepção do Ambiente, v. 4, n. 1, p. 85-99, 14. 2019.

RODRIGUES, J. L. S.; MONTEIRO, A. G. S.; LIMA; E. K. A.; SILVA, G. B. Analysis of housing in the axes of accessibility and functionality of a housing unit designed for the elderly. Research, Society and Development, 9(5), 2020.

TESTON, E. F.; CALDAS, C. P.; MARCON, S. S. Condomínio para idosos: condições de vida e saúde de residentes nesta nova modalidade habitacional. Rev. Bras. geriatr. gerontol., Rio de Janeiro, v. 18, n. 3, p. 487-497. 2015.

TORRES, L. B. Unidad residencial para el adulto mayor. Monografia (Graduação). Colômbia: Pontifica Universidad Javeriana. Facultad de Arquitectura y Diseño. 2019. 60 p.

YOSHIDA, D. M.; MAGAGNIN, R. C. Identificação do grau de acessibilidade espacial em apartamentos destinados a idosos. Revista Nacional de Gerenciamento de Cidades, [S.I.], v. 4, n. 23, set. 2016.

WORLD HEALTH ORGANIZATION (WHO). Envelhecimento ativo: uma política de saúde. Tradução Suzana Gontijo. Brasília: Organização Pan-Americana da Saúde, 2005. 60p.

NOTA DO EDITOR (*): O conteúdo do artigo e as imagens nele publicadas são de responsabilidade do(s) autor(es). 